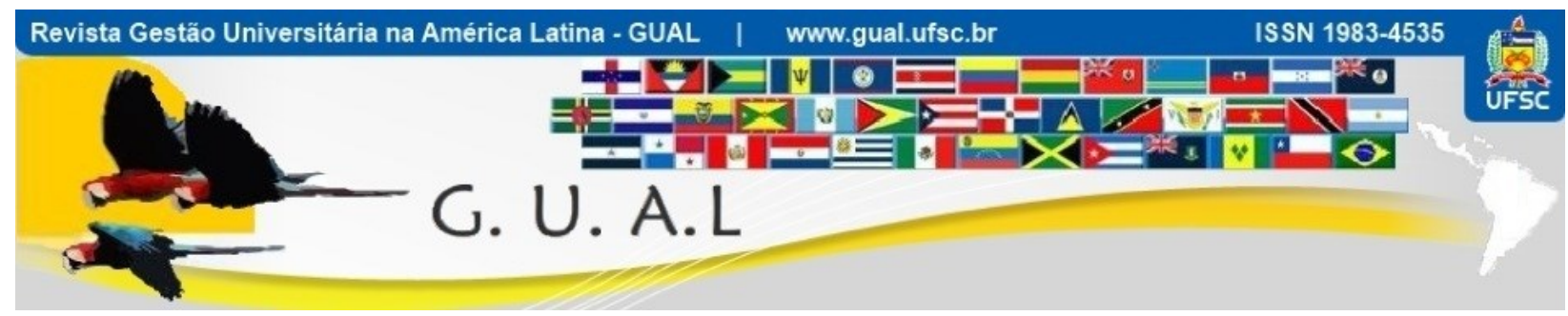

DOI: http://dx.doi.org/10.5007/1983-4535.2018v11n2p23

\title{
TEORIA OU PRÁTICA: O QUE ESPERAR DA DISSERTAÇÃO DE MESTRADO PROFISSIONAL EM ADMINISTRAÇÃO?
}

\section{THEORY OR PRACTICE: WHAT TO EXPECT FROM THE PROFESSIONAL MASTER'S THESIS IN ADMINISTRATION?}

Patricia Viveiros de Castro Krakauer, Doutora Centro Universitário Campo Limpo Paulista - UNIFACCAMP patricia.krakauer@,faccamp.br

Jane Aparecida Marques, Doutora Universidade de São Paulo - USP janemarq@usp.br

Martinho Isnard Ribeiro de Almeida, Doutor Universidade de São Paulo - USP martinho@usp.br

Recebido em 23/agosto/2016

Aprovado em 26/fevereiro/2018

Sistema de Avaliação: Double Blind Review 


\title{
RESUMO
}

Cursos de mestrado, no Brasil, da modalidade stricto sensu podem ser acadêmicos ou profissionais, sendo que estes últimos representam uma modalidade voltada para a capacitação de profissionais. Artigos anteriores recentes buscaram avaliar a importância dessa modalidade à luz da comparação com cursos acadêmicos, porém, não avançaram na discussão sobre os trabalhos de conclusão de curso de mestrados profissionais. Para tanto, foi desenvolvida uma diretriz, respaldada na teoria da aprendizagem experiencial, aplicada a alunos ingressantes em 2014 e 2015 no mestrado profissional da Faculdade de Economia, Administração e Contabilidade da Universidade de São Paulo. A atual pesquisa, que tem como motivador a percepção da necessidade de se ter uma lógica diferenciada para a elaboração dos trabalhos de conclusão de mestrados profissionais, buscou investigar se essa diretriz está sendo utilizada pelos alunos em seus projetos. A pesquisa ocorreu em dois momentos distintos: o primeiro objetivou o desenvolvimento da diretriz a ser testada e no segundo foi realizada uma pesquisa documental com 37 projetos de discentes, por meio de análise de conteúdo. Pôde-se concluir que a diretriz foi utilizada parcialmente pelos alunos, carecendo de evoluir no que se refere à inserção da criatividade, reflexão da experiência e relação entre a teoria e a prática.

Palavras-chave: Administração. Mestrado profissional. Trabalho de conclusão.

\begin{abstract}
Strict sense mastership courses in Brazil can be academic or professional, being the latter ones representative of a type focused on the training of professionals. Previous recent articles sought to evaluate the importance of this modality in comparison with academic courses; however, they have not advanced in the discussion on the term papers of professional mastership courses. For this, a guideline was developed, supported by experiential learning theory, applied to students entering the professional master's degree, between 2014 and 2015, from School of Economics, Business and Accounting of the University of São Paulo FEAUSP. The current research, motivated by the perceived need to have a different logic for the preparation of the term paper at professional masters, sought to investigate whether students in their projects are using this guideline. The research took place in two distinct phases: the first aimed to develop the guidelines to be tested and in the second was carried out a documentary research with 37 students' projects, being these documents analyzed using content analysis. We concluded that the guideline was partially used by students, lacking evolution when concerning the inclusion of creativity, the observation of experiences and the relationship between theory and practice.
\end{abstract}

Keywords: Administration. Professional mastership. Term paper. 


\section{INTRODUÇÃO}

Os cursos de mestrado, no Brasil, da modalidade stricto sensu podem ser acadêmicos ou profissionais, e estes últimos foram regulamentados pela Comissão de Aperfeiçoamento de Pessoal do Nível Superior (CAPES) pela Portaria ${ }^{\circ} 80$ de novembro de 1998 e pela Portaria Normativa $\mathrm{n}^{\mathrm{o}} 17$ de 28 de dezembro de 2009. No entanto, antes mesmo dessa Portaria, já havia alguns cursos de mestrado profissional oferecidos por diferentes instituições de ensino superior, sejam estas públicas ou privadas, reconhecidos pelo Conselho Nacional de Educação do Ministério da Educação. É esse Conselho que autoriza, reconhece e renova os reconhecimentos dos cursos de mestrado profissional de acordo com a legislação (CNE/CES, 2001, 2002).

O mestrado profissional trata-se de uma "modalidade de pós-graduação stricto sensu voltada para a capacitação de profissionais, nas diversas áreas do conhecimento, mediante o estudo de técnicas, processos, ou temáticas que atendam a alguma demanda do mercado de trabalho", conforme definido pela Capes (2014). E, como destaca Fischer (2003, p. 120), "foi concebido como um curso de natureza qualitativamente diferente, não como uma variante do mestrado acadêmico".

Essa modalidade faz parte da realidade nacional, em praticamente todas as áreas do conhecimento. Este estudo trata apenas dos mestrados profissionais da área de Administração, que têm suas particularidades, mas também devem atender aos objetivos previstos na referida Portaria (BRASIL, 2009): (i) capacitar profissionais qualificados para o exercício da prática profissional avançada e transformadora de procedimentos; (ii) transferir conhecimento para a sociedade; (iii) promover a articulação integrada da formação profissional com entidades demandantes de naturezas diversas; e (iv) contribuir para agregar competitividade e aumentar a produtividade em empresas, organizações públicas e privadas.

Para atender a esses objetivos, as propostas de mestrado profissional devem ter uma estrutura curricular que possibilitem a conexão entre conhecimento atualizado, metodologia pertinente e aplicação para a área de atuação profissional do curso, diferenciando-se de programas puramente acadêmicos.

É interessante notar que estudos anteriores já trataram da importância da modalidade do mestrado profissional na área de Administração, enfatizando que por se tratar de ciência social aplicada, os trabalhos finais devem atender a questões derivadas da 'administração prática’ (ALPERSTEDT et al., 2014; VASCONCELOS; VASCONCELOS, 2010). 
Estudos também já compararam as modalidades de mestrado profissional e acadêmico (ALPERSTEDT et al., 2014; FESTINALLI, 2005; RIBEIRO, 2005, 2006; RUAS, 2003), em especial, pelos critérios de avaliações e o profissional que está sendo formado (RIBEIRO, 2005, 2006; RUAS, 2003). Não cabe aqui tratar das especificidades do mestrado profissional, que envolvem julgamento e critérios próprios, deliberados pelas áreas de avaliação e subcomissões designadas, embora ainda precisem de definições mais específicas. Barros, Valentim e Melo (2005, p. 131) também caracterizam o mestrado profissional pela capacitação prática "por meio da incorporação do método científico", mas deixam uma lacuna no que se refere à integração entre os objetivos de um programa de mestrado profissional e a necessidade do trabalho de conclusão de curso seguir métodos considerados científicos, dado ser um curso stricto sensu. Trata-se, portanto, de avançar na compreensão da lógica do trabalho de final do curso, que deve estar vinculado às questões reais da área e finalidade do curso e pode ser apresentado em diferentes formatos (FESTINALLI, 2005), como dissertação, artigo, patente, publicações tecnológicas, protótipos, softwares, entre outras possibilidades.

A percepção da necessidade de se ter uma lógica diferenciada para a elaboração dos trabalhos de conclusão de mestrados profissionais foi o motivador da presente pesquisa que possui como objetivo avaliar os trabalhos de conclusão de curso em andamento no caso do mestrado profissional em empreendedorismo (MPE), da Faculdade de Economia, Administração e Contabilidade (FEA) da Universidade de São Paulo (USP), elaborados a partir de uma diretriz desenvolvida especificamente para este fim. Busca-se verificar se a diretriz proposta para a elaboração dos projetos de pesquisa no mestrado profissional em empreendedorismo da FEA-USP está sendo utilizada pelos alunos em seus projetos.

Justifica-se a pesquisa em vistas de ser um tema atual, dado o crescimento dos mestrados profissionais em Administração na cidade de São Paulo, ainda carente de maturidade e convergência empírica. Contribui academicamente como um passo no entendimento de um tema ainda em evolução e, na prática, com os demais programas de mestrados profissionais que passam pelos mesmos questionamentos e com docentes de metodologia e orientadores de futuros mestres que podem se apropriar de uma diretriz que tem sido utilizada em um programa existente que, apesar de recente - data de 2014 o seu início -, é oferecido em uma instituição tradicionalmente de excelência na área em questão. 


\section{MESTRADOS PROFISSIONAIS EM ADMINISTRAÇÃO}

De acordo com a classificação da Capes, dentro da grande área Ciências Sociais Aplicadas estão agregados os cursos de Administração, Ciências Contábeis e Turismo como uma única área de avaliação. Para este estudo considerou-se apenas os cursos de mestrados profissionais cadastrados na área de Administração, atendendo ao objetivo principal deste trabalho.

No documento de área da CAPES (2013), a área de Administração, Ciências Contábeis e Turismo, em 2012, na última Avaliação Trienal, realizada em 2013, havia 131 programas de pós-graduação, mas destes apenas 121 foram avaliados nessa Trienal, por funcionarem há mais de um ano. Dos 131 programas citados, 50 eram de mestrados profissionais. Atualmente tem-se um total de 56 mestrados profissionais cadastrados no site da Capes, no entanto, em 12 não consta a data de início, por serem recentes, ou seja, iniciados depois de 2013, e por isso ainda não foram homologados pelo Conselho Nacional de Educação do Ministério da Educação - CNE/MEC.

Pelo artigo $3^{\circ}$ da Portaria Normativa n. 17, de 28 de dezembro de 2009, a modalidade mestrado profissional parte da experiência prática do discente, e deve ser levado às atividades e produções técnico-científicas e de inovação em pesquisa aplicada, bem como na solução de problemas específicos da área de formação.

Tomando-se por base os dados destacados pela Comissão de Avaliação da Capes, na Avaliação Trienal de 2013, pode-se constatar que das propostas aprovadas de mestrado profissional, somente dois cursos tangenciavam as áreas de Inovação e/ou Empreendedorismo como área de concentração, conforme apresentado no Quadro 1, dentre estes está o curso de Empreendedorismo da FEA-USP, que será utilizado como parâmetro de análise neste trabalho, e o da Fundação Pedro Leopoldo - FPL, instituição privada localizada em Minas Gerais. 
Quadro 1 Relação dos Mestrados Profissionais na Área de Administração, com Área de Concentração em Inovação e/ou Empreendedorismo

\begin{tabular}{|c|c|c|c|c|c|l|}
\hline Programa & IES & UF & Nota & Início & $\begin{array}{c}\text { Área de } \\
\text { Concentração }\end{array}$ & Linhas de Pesquisa \\
\hline Administração & FPL & MG & 3 & 2000 & $\begin{array}{l}\text { Gestão da Inovação } \\
\text { e Competitividade }\end{array}$ & $\begin{array}{l}\text { ・ Inovação e } \\
\text { Organizações } \\
\text { Competitividade e } \\
\text { Marketing }\end{array}$ \\
\hline $\begin{array}{c}\text { Empreende- } \\
\text { dorismo }\end{array}$ & USP & SP & 3 & $(* *)$ & Empreendedorismo & $\begin{array}{l}\text { Inovação e Novos } \\
\text { Negócios } \\
\text { Empreendedorismo } \\
\text { Interno }\end{array}$ \\
\hline
\end{tabular}

(**) Ainda não homologado pelo CNE/MEC.

Fonte: Dados coletados no Sistema Nacional de Pós-Graduação, CAPES, MEC. Atualizado em: mar. 2015.

No entanto, há outros três cursos que se aproximam dessas áreas de Inovação e Empreendedorismo (Quadro 2), se consideradas algumas linhas de pesquisas, como demonstrado no quadro a seguir. Destes, dois são de instituições privadas (Pontifícia Universidade Católica de Minas Gerais e Faculdade Campo Limpo Paulista - FACCAMP, localizada no estado de São Paulo) e uma instituição federal (Universidade Federal de São Carlos - UFSCAR).

Quadro 2 Relação dos Mestrados Profissionais na Área de Administração, com Linhas de Pesquisa em Inovação e/ou Empreendedorismo

\begin{tabular}{|c|c|c|c|c|c|c|}
\hline Programa & IES & $\mathbf{U F}$ & Nota & Início & $\begin{array}{c}\text { Área de } \\
\text { Concentração }\end{array}$ & Linhas de Pesquisa \\
\hline Administração & $\mathrm{PUC} / \mathrm{MG}$ & MG & 5 & 2000 & $\begin{array}{l}\text { Gestão Estratégica } \\
\text { das Organizações }\end{array}$ & $\begin{array}{l}\text { - Pessoas, Trabalho e } \\
\text { Sociedade } \\
\text { - Estratégia e Marketing } \\
\text { - Inovação e } \\
\text { Conhecimento } \\
\end{array}$ \\
\hline $\begin{array}{c}\text { Administração } \\
\text { das Micro e } \\
\text { Pequenas } \\
\text { Empresas }\end{array}$ & FACCAMP & $\mathrm{SP}$ & 4 & 2009 & $\begin{array}{l}\text { Administração das } \\
\text { Micro e Pequenas } \\
\text { Empresas }\end{array}$ & $\begin{array}{l}\text { - Dinâmica das Micro e } \\
\text { Pequenas empresas } \\
\text { - Empreendedorismo e } \\
\text { Desenvolvimento } \\
\end{array}$ \\
\hline Administração & FPL & MG & 3 & 2000 & $\begin{array}{l}\text { Gestão da Inovação } \\
\text { e Competitividade }\end{array}$ & $\begin{array}{ll}\text { - } & \text { Inovação e } \\
\text { Organizações } \\
\text { - Competitividade e } \\
\text { Marketing } \\
\end{array}$ \\
\hline $\begin{array}{l}\text { Empreende- } \\
\text { dorismo }\end{array}$ & USP & $\mathrm{SP}$ & 3 & $(* *)$ & Empreendedorismo & $\begin{array}{l}\text { - Inovação e Novos } \\
\text { Negócios } \\
\text { - Empreendedorismo } \\
\text { Interno } \\
\end{array}$ \\
\hline
\end{tabular}




\begin{tabular}{|c|c|c|c|c|c|l|}
\hline Programa & IES & UF & Nota & Início & $\begin{array}{c}\text { Área de } \\
\text { Concentração }\end{array}$ & Linhas de Pesquisa \\
\hline $\begin{array}{c}\text { Gestão de } \\
\text { Organizações e } \\
\begin{array}{c}\text { Sistemas } \\
\text { Públicos }\end{array}\end{array}$ & UFSCAR & SP & 3 & 2015 & $\begin{array}{l}\text { Gestão de Organizações } \\
\text { Públicas }\end{array}$ \\
$\begin{array}{l}\text { Gestão de } \\
\text { Organizações e } \\
\text { Sistemas Públicos }\end{array}$ & $\begin{array}{l}\text { Ciência, Tecnologiticas de } \\
\text { Inovação } \\
\text { Estado e Políticas } \\
\text { Públicas }\end{array}$ \\
\hline
\end{tabular}

(**) Ainda não homologado pelo CNE/MEC.

Fonte: Dados coletados no Sistema Nacional de Pós-Graduação, CAPES, MEC. Atualizado em: mar. 2015.

O que chama a atenção nesses quadros 1 e 2 é a concentração desses cursos na região Sudeste, em especial, São Paulo e Minas Gerais. O Mestrado Profissional em Empreendedorismo da FEA-USP é, no entanto, o único totalmente direcionado aos temas de Inovação e Empreendedorismo e tem tomado iniciativas pioneiras na discussão dos propósitos dos mestrados profissionais em Administração. Por dois anos consecutivos - 2014 e 2015 foi realizado o Encontro de Mestrados Profissionais nessa mesma instituição e, dentre os temas discutidos nesse evento, o trabalho de conclusão de curso esteve na pauta de discussões, sendo que tais discussões têm sido recorrentes entre os docentes e discentes do programa.

Para atender ao desconforto de docentes e discentes acerca da lógica dos projetos de dissertação do mestrado profissional em estudo, foi desenvolvida uma diretriz para a estruturação de tais trabalhos, respaldada na teoria de aprendizagem experiencial (KOLB, 1984), que será tratada no item 3 do presente artigo.

\section{ESTRATÉGIA METODOLÓGICA}

Dada a excelência tradicionalmente cunhada à Universidade de São Paulo no contexto do nosso país, o pioneirismo do programa de mestrado profissional existente na Faculdade de Economia, Administração e Contabilidade e as recorrentes discussões sobre a lógica dos projetos de dissertação de cunho profissional existentes entre o corpo docente da instituição, considerou-se o caso interessante à luz das contribuições tanto acadêmicas quanto práticas, sendo a relevância um dos aspectos citados por Mariotto et al. (2014) para estudos de casos únicos.

Caracteriza-se como uma pesquisa de natureza exploratória por ter como objetivo principal a ampliação do conhecimento sobre determinado fenômeno, ainda carente de 
investigação (SELLTIZ et al., 1987), com abordagem qualitativa por não buscar testar aquilo que já se conhece (FLICK, 2009, p. 24). A pesquisa ocorreu em duas fases distintas:

1. A primeira fase tinha como objetivo formalizar a diretriz para os trabalhos de conclusão de curso que já vinha sendo adotada na instituição em questão e, para tal, foi realizado um levantamento na base de dados da CAPES sobre mestrados profissionais em administração e uma investigação teórica sobre a aprendizagem experiencial, alicerce do desenvolvimento da diretriz, cujos resultados são apresentados nos próximos itens do atual artigo.

2. Na segunda fase, correspondente a pesquisa de campo, foi realizada uma pesquisa documental através de relatos de pesquisa (GIL, 2010, 2012) correspondentes aos projetos elaborados pelos alunos, seguida de uma análise de conteúdo, buscando atender ao objetivo delineado no presente trabalho e o questionamento apresentado no item introdutório.

A pesquisa de campo ocorreu em dois momentos distintos durante o ano de $2015-1^{\circ}$. e $2^{\circ}$. Semestres -, sendo enviadas solicitações aos 40 alunos que ingressaram em 2014 e 2015 no programa do Mestrado Profissional em Empreendedorismo (MPE) da Faculdade de Economia, Contabilidade e Administração (FEA) da Universidade de São Paulo (USP), de modo que os projetos de pesquisa elaborados em disciplina específica para esta finalidade fossem analisados. Foram recebidos 37 aceites (18 aceites dos alunos que ingressaram em 2014 e 19 dos ingressantes em 2015), sendo que esses trabalhos passaram a se constituir como corpus deste estudo, preservando as identidades dos colaboradores. Para efeito de análise, os trabalhos foram divididos conforme as turmas que pertenciam e numerados sequencialmente, a saber, turma A corresponde aos projetos elaborados pelos ingressantes em 2014 e turma B ao grupo que ingressou em 2015. Dessa forma, os projetos foram codificados de A1 a A18 e de B1 a B19.

Para a análise dos projetos foi realizada a análise de conteúdo através da conceituação de Bardin (1977, 2006), a saber: (1) análise prévia: foi realizada a organização do material coletado através da leitura, seleção e classificação do material; (2) exploração do material: foi efetivada a descrição analítica através da codificação do material por categorias (Quadro 3); e (3) tratamento dos resultados, inferência e interpretação, por meio de análise reflexiva.

As categorias de análise foram definidas a partir de: (1) ciclo da pesquisa que será apresentado no item 3 (Figura 2), (2) diretriz proposta para a elaboração dos trabalhos na disciplina 'plano de intervenção', discutida no item pertinente e (3) objetivos dos mestrados profissionais apresentados na portaria normativa (BRASIL, 2009). 
Duas categorias foram analisadas de forma genérica, uma pela necessidade de avaliar a completude da disciplina e a outra, a criatividade, em função da temática do programa.

Quadro 3 Categorias utilizadas para a análise de conteúdo

\begin{tabular}{|c|c|c|c|}
\hline Base & Categoria & Descrição & Indicadores \\
\hline Genérica & $\begin{array}{l}\text { Realização do } \\
\text { projeto }\end{array}$ & $\begin{array}{c}\text { O aluno elaborou o trabalho no prazo } \\
\text { estipulado. }\end{array}$ & Sim ou Não \\
\hline Genérica & $\begin{array}{l}\text { Criatividade na } \\
\text { estrutura }\end{array}$ & $\begin{array}{l}\text { O aluno apresentou novos elementos } \\
\text { aos apresentados em sala de aula. }\end{array}$ & $\begin{array}{l}\text { Presença ou } \\
\text { Ausência }\end{array}$ \\
\hline $\begin{array}{l}\text { Diretriz proposta na } \\
\text { disciplina }\end{array}$ & Funil de pesquisa & $\begin{array}{l}\text { O aluno entendeu a proposta da } \\
\text { elaboração do funil de pesquisa, } \\
\text { apresentando o capítulo introdutório } \\
\text { condizente com esta estrutura. }\end{array}$ & Sim ou Não \\
\hline $\begin{array}{c}\text { Objetivo do } \\
\text { mestrado } \\
\text { profissional e etapa } \\
1 \text { do ciclo de } \\
\text { pesquisa. } \\
\end{array}$ & $\begin{array}{c}\text { Adequação do } \\
\text { Projeto à } \\
\text { Experiência } \\
\text { Profissional/ Há } \\
\text { relato da experiência } \\
\end{array}$ & $\begin{array}{c}\text { A experiência profissional do aluno é } \\
\text { destacada no projeto de pesquisa } \\
\text { apresentado. }\end{array}$ & Sim ou Não \\
\hline $\begin{array}{l}\text { Etapa } 2 \text { do ciclo da } \\
\text { pesquisa }\end{array}$ & $\begin{array}{l}\text { Reflexão sobre a } \\
\text { experiência }\end{array}$ & $\begin{array}{c}\text { O aluno apresentou uma reflexão } \\
\text { sobre a experiência, destacando o } \\
\text { problema de pesquisa. }\end{array}$ & Sim ou Não \\
\hline $\begin{array}{l}\text { Diretriz proposta na } \\
\text { disciplina }\end{array}$ & $\begin{array}{c}\text { Busca de } \\
\text { embasamento teórico }\end{array}$ & $\begin{array}{l}\text { O aluno entendeu a proposta da } \\
\text { elaboração do funil da teoria, } \\
\text { apresentando a revisão teórica } \\
\text { condizente com esta estrutura. }\end{array}$ & Sim ou Não \\
\hline $\begin{array}{l}\text { Etapa } 3 \text { do ciclo da } \\
\text { pesquisa }(*)\end{array}$ & $\begin{array}{l}\text { Relação teoria e } \\
\text { prática }\end{array}$ & $\begin{array}{l}\text { O aluno apresenta a relação entre } \\
\text { teoria e prática. }\end{array}$ & Sim ou Não \\
\hline $\begin{array}{l}\text { Objetivo do } \\
\text { mestrado } \\
\text { profissional }\end{array}$ & $\begin{array}{l}\text { Adequação à Área } \\
\text { de Concentração: } \\
\text { Empreendedorismo }\end{array}$ & $\begin{array}{l}\text { O projeto apresentado está alinhado à } \\
\text { área de concentração do Programa. }\end{array}$ & Sim ou Não \\
\hline $\begin{array}{l}\text { Objetivo do } \\
\text { mestrado } \\
\text { profissional }\end{array}$ & $\begin{array}{l}\text { Adequação à Linha } \\
\text { de Pesquisa: } \\
\text { Inovação e Novos } \\
\text { Negócios ou } \\
\text { Empreendedorismo } \\
\text { Interno }\end{array}$ & $\begin{array}{l}\text { O projeto apresentado está alinhado à } \\
\text { linha de pesquisa do Programa. }\end{array}$ & Sim ou Não \\
\hline
\end{tabular}

(*) Destaca-se que os alunos encerraram a disciplina na etapa 3 do ciclo da pesquisa, não realizando a quarta etapa.

De forma a resumir o método da hodierna pesquisa, tem-se os passos utilizados para a sua realização:

1. Levantamento no portal da CAPES acerca de mestrados profissionais em administração e investigação teórica da aprendizagem experiencial, objetivando formalizar uma diretriz para a elaboração dos trabalhos de conclusão de curso. 
2. Levantamento dos projetos entregues para a finalização da disciplina referentes a primeira e segunda turmas do MPE da FEA-USP, ou seja, alunos ingressantes em 2014 e 2015.

3. Envio de e-mail ao aluno autor do projeto, solicitando autorização para a realização da análise do mesmo para a turma A e apresentação de carta coletiva para a turma $\mathrm{B}$, assinada presencialmente por aqueles que assim o desejassem.

4. Definição das categorias de análise, considerando as regras definidas por Bardin (1977): exclusão mútua, homogeneidade, pertinência, objetividade e representatividade.

5. Avaliação de cada projeto por meio da análise de conteúdo, pelos pesquisadores separadamente, com o objetivo de ter no mínimo uma dupla avaliação.

6. Comparação das análises realizadas, visando apurar se havia distinções na avaliação individual para eliminar possíveis vieses e/ou discrepâncias de subjetividade dos analistas.

7. Sistematização e comparação dos dados encontrados.

Optou-se por realizar a análise das categorias elencadas por ambos os pesquisadores em separado, de forma a garantir a validade de conteúdo, garantindo maior "precisão" dos dados (HAIR et al., 2005, p. 197).

\section{DIRETRIZ PARA O PROJETO DE PESQUISA DE MESTRADOS PROFISSIONAIS}

Como alicerce para a elaboração da diretriz que atendesse às necessidades dos discentes do programa de mestrado profissional em estudo foi utilizada a teoria da aprendizagem experiencial (TAE), cujos princípios norteadores são apresentados resumidamente a seguir.

\subsection{TEORIA DA APRENDIZAGEM EXPERIENCIAL (TAE)}

A aprendizagem experiencial proporciona uma visão diferenciada dos processos tradicionais baseados em uma epistemologia racional ou unicamente empírica, sendo o processo pelo qual o conhecimento é gerado a partir da transformação da experiência. Na gênese da aprendizagem experiencial estão os modelos de Dewey, Lewin e Piaget, que acreditam que a própria natureza do aprendizado preconiza uma relação de tensão e conflito através da interação do indivíduo com o seu ambiente (ANTONELLO, 2006; KOLB, 1984).

A teoria, proposta e testada por Kolb (1984) é voltada para o desenvolvimento da profissionalidade e recomendada pelo autor para uso na pós-graduação, em treinamentos 
corporativos ou similares, dada a necessidade de se ter vivenciado previamente uma experiência concreta ou vivenciá-la durante o processo de aquisição do conhecimento. Isto porque a TAE utiliza a experiência como central ao aprendizado, consistente com o modo como as pessoas adultas aprendem e se desenvolvem (BAKER, JENSEN, KOLB, 2005).

Composta por quatro etapas relacionadas em dois eixos dialéticos - experiência concreta (EC), observação reflexiva (OR), conceptualização abstrata (CA) e experimentação ativa (EA) - a teoria preconiza uma estrutura holística de aprendizado, representada no que se chamou como ciclo de Kolb e pode ser visualizado na Figura 1.

A aprendizagem ocorre não apenas da experiência prática, mas sim da reflexão sobre a mesma e da resolução de conflitos entre o abstrato e o concreto e entre a ação e a reflexão. A experiência per si não gera conhecimento, mas a reflexão prático-teórica sobre a mesma, o que traz uma proximidade ao que se é esperado em programas de Mestrados Profissionais.

Figura 1 Ciclo de Kolb

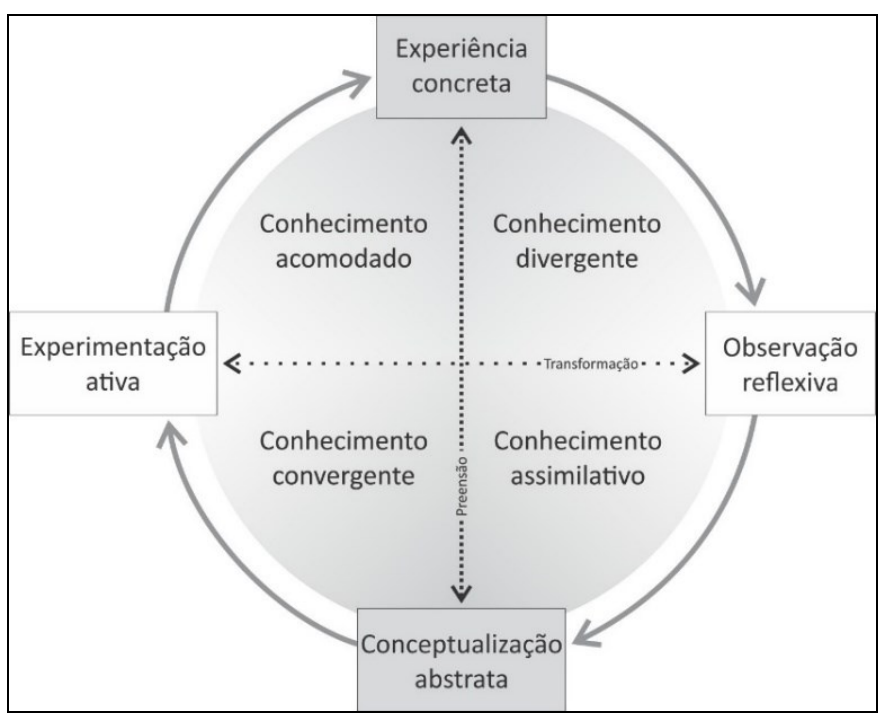

Fonte: elaborado a partir de KOLB (1984)

A experiência concreta (EC) é o 'fazer', em que o estudante é um participante ativo; a observação reflexiva (OR) é o 'observar', ou seja, o estudante reflete conscientemente sobre a experiência; a conceptualização abstrata (CA) é o momento do 'pensar', no qual o estudante procura entender as teorias e conceitos relacionados e a experimentação ativa (EA) é o planejamento de como o estudante irá utilizar os conceitos teóricos em sua prática (SHARLANOVA, 2004). 
Como comentado acima, no ciclo kolbiano observa-se a relação dialética entre abstrato e concreto, resolvida através da preensão, que comporta dois aspectos opostos - apreensão e compreensão - de modo que o indivíduo possa se reportar à experiência e relatá-la. A outra relação diz respeito ao reflexivo e ativo que se manifesta na aprendizagem por transformação, por meio da observação reflexiva e da experimentação ativa, com o propósito de permitir a reconstrução de significados do estudante (PIMENTEL, 2007).

As relações entre essas quatro possibilidades existentes nos dois eixos dialéticos resultam em quatro possíveis estilos de aprendizagem: acomodador, divergente, assimilativo e convergente. Além disso a teoria possui seis proposições que são consideradas por Kolb (1984) e reafirmadas por Kolb e Kolb (2005) como os pilares da teoria, a saber:

(1) Aprendizagem é mais bem concebida como um processo, não como resultados: a teoria experiencial nasce de diferentes suposições, pelas quais as ideias não são fixas, ao contrário, são formadas e reformadas a partir da experiência.

(2) Aprendizagem é um processo contínuo, fundamentada na experiência: sugere que todo aprendizado é uma forma de reconstrução de significados e que todo aprendiz não é como um papel vazio, mas que todos iniciam uma situação de aprendizado com ideias articuladas sobre determinado tópico.

(3) $\mathrm{O}$ processo de aprendizagem requer a resolução de conflitos entre elementos dialeticamente opostos: a aprendizagem requer habilidades que são opostas e a forma como será resolvido o conflito entre os modos opostos é que ditará o nível de aprendizado resultante.

(4) Aprendizagem é um processo holístico de adaptação ao mundo: para transformar a experiência em aprendizagem é essencial combinar experiência, percepção, cognição e comportamento.

(5) Aprendizagem envolve o relacionamento entre o indivíduo e o ambiente: O processo de aprendizagem é a transação entre o ser e o meio, promovendo o entrelaçamento de ambos de forma a constituir um novo elemento.

(6) Aprendizagem é o processo de criação de conhecimento: a aprendizagem experiencial possui uma abordagem prática de resolução de problemas, do senso comum e da interpretação em busca da aquisição do conhecimento.

Vislumbrou-se a possibilidade de utilização da TAE como pilar para o desenvolvimento de uma diretriz para a elaboração dos projetos de pesquisa de mestrados profissionais em Administração, sendo a que será apresentada a seguir foi desenvolvida para o programa existente na FEA-USP. 


\subsection{DIRETRIZ PROPOSTA}

Entendendo que as dissertações do mestrado profissional não poderiam seguir a mesma lógica do mestrado acadêmico e utilizando o ciclo de Kolb, apresentado no item anterior, como fundamento, os autores da presente pesquisa desenvolveram uma proposição de diretriz para a elaboração dos projetos de pesquisa dos alunos participantes do Mestrado Profissional em Empreendedorismo da FEA-USP que passa, então, a ser investigado empiricamente, de forma que sua aplicação possa ser utilizada por outros programas que assim o considerem.

Destaca-se que o Mestrado Profissional em Empreendedorismo da FEA-USP, cadastrado na grande área Administração, Ciências Contábeis e Turismo, em funcionamento desde o início de 2014, tem como formato a elaboração de uma dissertação, dada as características do próprio curso, voltado a aspectos de gestão.

Os trabalhos acadêmicos possuem como ponto de partida uma lacuna teórica vislumbrada pelo pesquisador após a leitura e pesquisa de temáticas que estejam na fronteira do conhecimento ou carentes de validação empírica. No caso do mestrado profissional em questão, resguardaram-se os preceitos da metodologia científica, mas o trabalho nasce da experiência concreta vivenciada pelo aluno no mundo empresarial - denominada como relato da experiência -, seguindo o preconizado por Kolb (1984), e estabelecendo a experiência como primeira etapa do ciclo. Esse ciclo (vide Figura 1) fundamentou teoricamente a elaboração do ciclo para a pesquisa do mestrado profissional em empreendedorismo (Figura 2).

Pelo ciclo elaborado para o mestrado profissional, o projeto de pesquisa nasce do relato da experiência prática do aluno, passa para a etapa 2 que seria a compreensão dessa experiência, do que foi vivenciado pelo discente e do qual problema prático carece de respostas. Na etapa 3 o aluno busca a teoria que embasará a sua problemática, estabelecendo conexões entre a prática e a teoria, e na etapa 4 o aluno avalia a experiência, entendendo a sua vivência à luz de teorias administrativas, voltando ao seu relato para contribuir com sugestões futuras. 
Figura 2 Ciclo da pesquisa no mestrado profissional em empreendedorismo

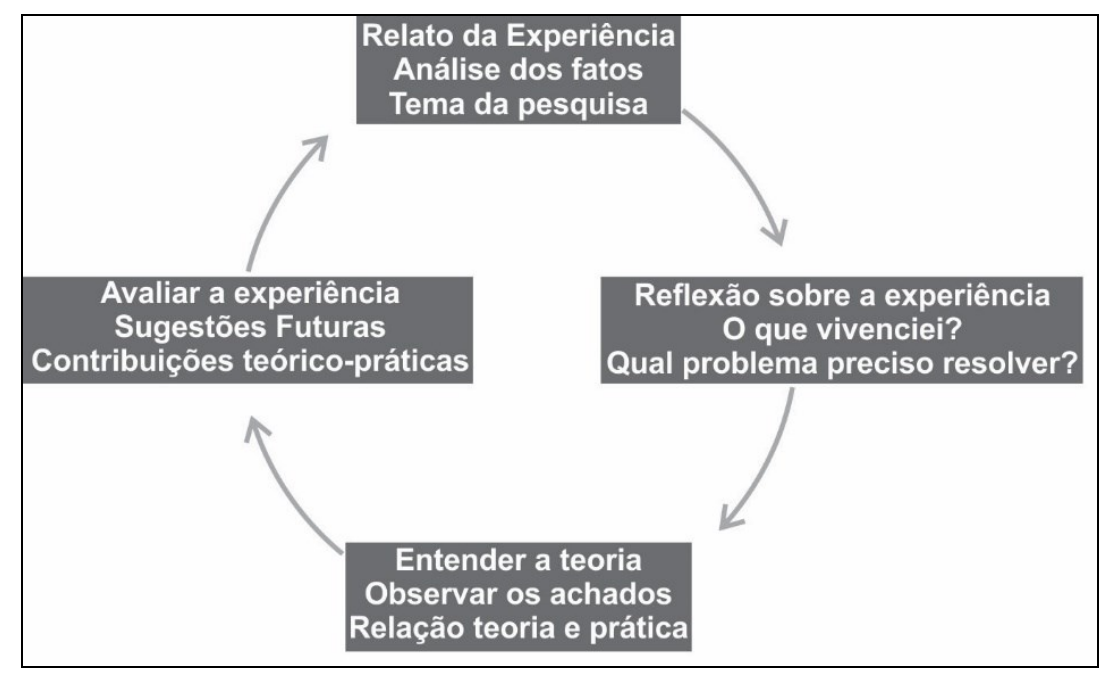

Com base nessa lógica foi, então, pensada a estrutura do projeto de pesquisa por meio do desenvolvimento de dois funis complementares. O primeiro, denominado como funil de pesquisa (Figura 3) estabelece a relação entre relato e problema, bem como a definição da questão de pesquisa e seus objetivos. O entendimento pelos discentes de que o problema é um recorte do que ocorreu na experiência vivenciada, ou seja, é a parte que será investigada em profundidade com a pesquisa, passou a ser mais fácil com a visualização do funil de pesquisa.

Figura 3 Funil da pesquisa para o mestrado profissional em empreendedorismo

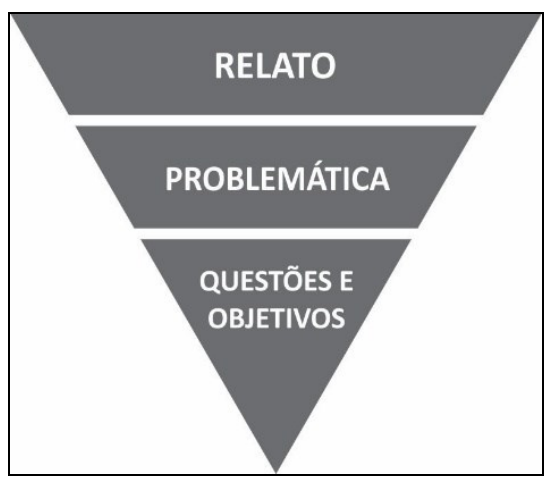

O segundo (Figura 4) apresenta o que também para o mestrado acadêmico é uma condição, o funil da teoria. Inicia-se com o tema mais abrangente para o mais específico e é essencial para que o mestrando possa estruturar o seu trabalho de conclusão de curso em termos tanto teóricos quanto práticos e contextuais. 
Figura 4 Funil da teoria para o mestrado profissional em empreendedorismo

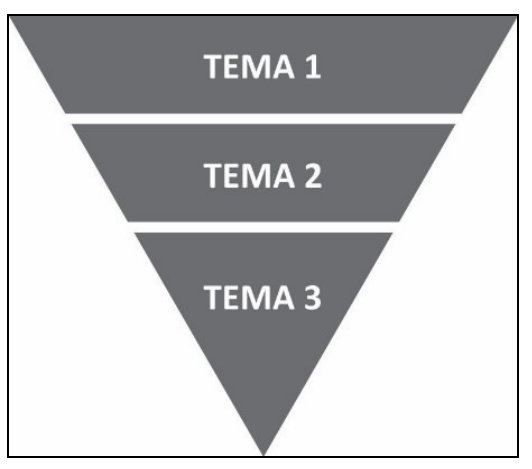

Ao se organizar ambos os funis em uma única pesquisa, percebe-se que a estruturação do projeto em formato de uma ampulheta (Figura 5), começa com um relato da experiência, (tema), estreita para uma problemática e para uma questão de pesquisa, explora essa questão a partir de uma reflexão teórica e conclui voltando à prática para mostrar a contribuição.

Figura 5 Lógica da dissertação do mestrado profissional em empreendedorismo

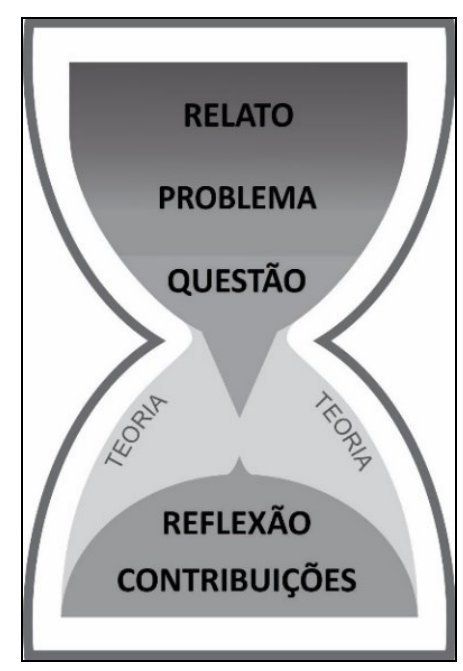

\section{ANÁLISE DOS PROJETOS}

De acordo com Bardin (1977), a análise de conteúdo pode utilizar das seguintes técnicas: análise categorial, análise de avaliação, análise de enunciação, análise de expressão, análise das relações e análise do discurso.

Neste estudo adotou-se a análise de relações proposta por Osgood (1959, apud BARDIN, 1977, p. 199), que se caracteriza pelas seguintes etapas: escolha das unidades de análise e categorização (temas), codificação de cada unidade em registros em cada unidade do contexto, e cálculo das co-ocorrências, considerando que "quanto maior for a frequência dos 
elementos, tanto maior será a sua importância, a co-ocorrência (ou a não co-ocorrência) de dois ou mais elementos revelaria a associação ou dissociação no espírito do locutor."

Considerando as categorias delineadas na estratégia metodológica apresentada - que trata da metodologia adotada (Quadro 3) -, realizou-se a análise dos trinta e sete projetos e as ocorrências são apresentadas no Quadro 4, de acordo com a análise realizada por cada um dos pesquisadores envolvidos tanto no desenvolvimento da diretriz quanto na elaboração do atual artigo.

Quadro 4 Resultados obtidos com a análise das categorias

\begin{tabular}{|c|c|c|c|}
\hline Categoria & Turma & Pesquisador 1 & Pesquisador 2 \\
\hline \multirow{3}{*}{ Realização do projeto } & A & $\begin{array}{l}\text { Sim }-18 \text { ocorrências } \\
\text { Não }- \text { zero ocorrência }\end{array}$ & $\begin{array}{l}\text { Sim - } 18 \text { ocorrências } \\
\text { Não - zero ocorrência }\end{array}$ \\
\hline & B & $\begin{array}{l}\text { Sim - } 19 \text { ocorrências } \\
\text { Não - zero ocorrência }\end{array}$ & $\begin{array}{l}\text { Sim }-19 \text { ocorrências } \\
\text { Não }- \text { zero ocorrência }\end{array}$ \\
\hline & Total & $\begin{array}{l}\text { Sim }-37 \text { ocorrências } \\
\text { Não }- \text { zero ocorrência }\end{array}$ & $\begin{array}{l}\text { Sim }-37 \text { ocorrências } \\
\text { Não - zero ocorrência }\end{array}$ \\
\hline \multirow{3}{*}{ Criatividade na estrutura } & A & $\begin{array}{l}\text { Presença }-05 \text { ocorrências } \\
\text { Ausência }-13 \text { ocorrências }\end{array}$ & $\begin{array}{l}\text { Presença }-05 \text { ocorrências } \\
\text { Ausência }-13 \text { ocorrências }\end{array}$ \\
\hline & B & $\begin{array}{l}\text { Presença }-05 \text { ocorrências } \\
\text { Ausência }-14 \text { ocorrências }\end{array}$ & $\begin{array}{l}\text { Presença }-04 \text { ocorrências } \\
\text { Ausência }-15 \text { ocorrências }\end{array}$ \\
\hline & Total & $\begin{array}{l}\text { Presença }-10 \text { ocorrências } \\
\text { Ausência }-27 \text { ocorrências }\end{array}$ & $\begin{array}{l}\text { Presença }-09 \text { ocorrências } \\
\text { Ausência }-28 \text { ocorrências }\end{array}$ \\
\hline \multirow{3}{*}{ Funil de pesquisa } & A & $\begin{array}{l}\text { Sim }-15 \text { ocorrências } \\
\text { Não }-03 \text { ocorrências }\end{array}$ & $\begin{array}{l}\text { Sim }-15 \text { ocorrências } \\
\text { Não }-03 \text { ocorrências }\end{array}$ \\
\hline & B & $\begin{array}{l}\text { Sim - } 18 \text { ocorrências } \\
\text { Não }-01 \text { ocorrência }\end{array}$ & $\begin{array}{l}\text { Sim - } 18 \text { ocorrências } \\
\text { Não }-01 \text { ocorrência }\end{array}$ \\
\hline & Total & $\begin{array}{l}\text { Sim }-33 \text { ocorrências } \\
\text { Não }-04 \text { ocorrências }\end{array}$ & $\begin{array}{l}\text { Sim }-33 \text { ocorrências } \\
\text { Não }-04 \text { ocorrências }\end{array}$ \\
\hline \multirow{3}{*}{$\begin{array}{l}\text { Adequação do Projeto à } \\
\text { Experiência Profissional/ Há } \\
\text { relato da experiência }\end{array}$} & A & $\begin{array}{l}\text { Sim }-16 \text { ocorrências } \\
\text { Não }-02 \text { ocorrências }\end{array}$ & $\begin{array}{l}\text { Sim }-16 \text { ocorrências } \\
\text { Não }-02 \text { ocorrências }\end{array}$ \\
\hline & B & $\begin{array}{l}\text { Sim }-19 \text { ocorrências } \\
\text { Não }- \text { zero ocorrência }\end{array}$ & $\begin{array}{l}\text { Sim - } 18 \text { ocorrências } \\
\text { Não }-01 \text { ocorrência }\end{array}$ \\
\hline & Total & $\begin{array}{l}\text { Sim }-35 \text { ocorrências } \\
\text { Não }-02 \text { ocorrências }\end{array}$ & $\begin{array}{l}\text { Sim }-34 \text { ocorrências } \\
\text { Não }-03 \text { ocorrências }\end{array}$ \\
\hline \multirow{3}{*}{ Reflexão sobre a experiência } & A & $\begin{array}{l}\text { Sim }-10 \text { ocorrências } \\
\text { Não }-08 \text { ocorrências }\end{array}$ & $\begin{array}{l}\text { Sim }-12 \text { ocorrências } \\
\text { Não }-06 \text { ocorrências }\end{array}$ \\
\hline & B & $\begin{array}{l}\text { Sim }-15 \text { ocorrências } \\
\text { Não }-04 \text { ocorrências }\end{array}$ & $\begin{array}{l}\text { Sim }-14 \text { ocorrências } \\
\text { Não }-05 \text { ocorrências }\end{array}$ \\
\hline & Total & $\begin{array}{l}\text { Sim }-25 \text { ocorrências } \\
\text { Não }-12 \text { ocorrências }\end{array}$ & $\begin{array}{l}\text { Sim }-26 \text { ocorrências } \\
\text { Não }-11 \text { ocorrências }\end{array}$ \\
\hline \multirow{3}{*}{ Busca de embasamento teórico } & A & $\begin{array}{l}\text { Sim }-15 \text { ocorrências } \\
\text { Não }-03 \text { ocorrências }\end{array}$ & $\begin{array}{l}\text { Sim }-17 \text { ocorrências } \\
\text { Não }-01 \text { ocorrência }\end{array}$ \\
\hline & B & $\begin{array}{l}\text { Sim }-17 \text { ocorrências } \\
\text { Não }-02 \text { ocorrências }\end{array}$ & $\begin{array}{l}\text { Sim }-19 \text { ocorrências } \\
\text { Não }- \text { zero ocorrência }\end{array}$ \\
\hline & Total & $\begin{array}{l}\text { Sim }-32 \text { ocorrências } \\
\text { Não }-05 \text { ocorrências }\end{array}$ & $\begin{array}{l}\text { Sim - } 36 \text { ocorrências } \\
\text { Não }-01 \text { ocorrência }\end{array}$ \\
\hline Relação teoria e prática & A & Sim -03 ocorrências & Sim -04 ocorrências \\
\hline
\end{tabular}




\begin{tabular}{|c|c|c|c|}
\hline Categoria & Turma & Pesquisador 1 & Pesquisador 2 \\
\hline & & Não -15 ocorrências & Não - 14 ocorrências \\
\hline & B & $\begin{array}{l}\text { Sim }-08 \text { ocorrências } \\
\text { Não }-11 \text { ocorrências }\end{array}$ & $\begin{array}{l}\text { Sim }-08 \text { ocorrências } \\
\text { Não }-11 \text { ocorrências }\end{array}$ \\
\hline & Total & $\begin{array}{l}\text { Sim }-11 \text { ocorrências } \\
\text { Não }-26 \text { ocorrências }\end{array}$ & $\begin{array}{l}\text { Sim }-12 \text { ocorrências } \\
\text { Não }-25 \text { ocorrências }\end{array}$ \\
\hline \multirow{3}{*}{$\begin{array}{l}\text { Adequação à Área de } \\
\text { Concentração: } \\
\text { Empreendedorismo }\end{array}$} & A & $\begin{array}{l}\text { Sim - } 18 \text { ocorrências } \\
\text { Não - zero ocorrência }\end{array}$ & $\begin{array}{l}\text { Sim }-18 \text { ocorrências } \\
\text { Não }- \text { zero ocorrência }\end{array}$ \\
\hline & B & $\begin{array}{l}\text { Sim - } 19 \text { ocorrências } \\
\text { Não - zero ocorrência }\end{array}$ & $\begin{array}{l}\text { Sim }-19 \text { ocorrências } \\
\text { Não }- \text { zero ocorrência }\end{array}$ \\
\hline & Total & $\begin{array}{l}\text { Sim - } 37 \text { ocorrências } \\
\text { Não - zero ocorrência }\end{array}$ & $\begin{array}{l}\text { Sim - } 37 \text { ocorrências } \\
\text { Não - zero ocorrência }\end{array}$ \\
\hline \multirow{3}{*}{$\begin{array}{c}\text { Adequação à Linha de } \\
\text { Pesquisa: Inovação e Novos } \\
\text { Negócios ou } \\
\text { Empreendedorismo Interno }\end{array}$} & A & $\begin{array}{l}\text { Sim - } 18 \text { ocorrências } \\
\text { Não - zero ocorrência }\end{array}$ & $\begin{array}{l}\text { Sim - } 18 \text { ocorrências } \\
\text { Não }- \text { zero ocorrência }\end{array}$ \\
\hline & B & $\begin{array}{l}\text { Sim - } 19 \text { ocorrências } \\
\text { Não - zero ocorrência }\end{array}$ & $\begin{array}{l}\text { Sim }-19 \text { ocorrências } \\
\text { Não }- \text { zero ocorrência }\end{array}$ \\
\hline & Total & $\begin{array}{l}\text { Sim - } 37 \text { ocorrências } \\
\text { Não - zero ocorrência }\end{array}$ & $\begin{array}{l}\text { Sim - } 37 \text { ocorrências } \\
\text { Não - zero ocorrência }\end{array}$ \\
\hline
\end{tabular}

Percebe-se que, de uma forma geral, os projetos atenderam a diretriz desenvolvida para a disciplina em questão, foram entregues no prazo e em conformidade ao solicitado pelos professores. As demais categorias serão analisadas, qualitativamente, a seguir:

\subsection{Criatividade na estrutura}

A criatividade na estrutura, ou seja, a inserção de novos elementos aos propostos pelos professores da disciplina, não despontou na maioria dos projetos analisados de ambas as turmas, sendo que uma minoria incluiu novas possibilidades estruturais. Ao se analisar os projetos que apresentaram a presença da criatividade, percebe-se que trouxeram uma maior proximidade com o contexto investigado, inserindo dados de mercado que não foram solicitados na diretriz proposta e discutida no item correspondente do presente artigo.

A inserção dos dados do mercado ou do setor ilustrou o relato da experiência e promoveu um maior entendimento da problemática delineada nos projetos, projetando a reflexão do aluno para além da experiência vivenciada. Trata-se, pois, da investigação de dados secundários que, no caso de trabalhos de cunho dissertativo como os analisados, favorece um olhar mais holístico da essência do relato profissional e embasa as informações inseridas na contextualização da pesquisa. 


\subsection{Funil de Pesquisa}

O funil de pesquisa, apresentado na Figura 3, tem como proposta facilitar para o aluno o entendimento estrutural de um trabalho dissertativo, de cunho profissional, que busca entender a teoria a partir da prática vivenciada pelo mestrando. Foram ministradas várias aulas explicitando a diretriz proposta, em específico sobre os dois funis de pesquisa, e os resultados foram positivos. A maioria dos alunos apresentou um relato proveniente de uma experiência concreta vivenciada, seguido de uma problemática percebida que os levou para uma questão de pesquisa e os consequentes objetivos - geral e secundários. Em se considerando que poucos eram os alunos que tinham conhecimento de metodologia científica utilizada para a pesquisa em programas de pós-graduação stricto sensu, considerou-se que o funil de pesquisa foi bem aplicado nos projetos analisados.

Alguns dos trabalhos, pode-se citar o A16 como exemplo, não conseguiu, dentro da situação problema, realizar um recorte adequado a uma investigação de cunho científico, principalmente pela natureza profissional da mesma, na qual é pertinente a inserção de uma visão integrada de vários temas dentro do contexto relatado. Neste ponto, vale o comentário de que o recorte e aprofundamento que discentes e pesquisadores de programas acadêmicos realizam em seus trabalhos nem sempre é possível no trabalho com enfoque profissional, cuja solução da problemática depende, em alguns casos, da composição de vários aspectos teóricos.

\subsection{Adequação do Projeto à Experiência Profissional}

Atendendo aos objetivos de mestrados profissionais, apresentados em portaria específica (BRASIL, 2009), a experiência profissional e o desenvolvimento de habilidades que as aprimore é essencial para programas de mestrado profissional. Por isso, a diretriz proposta pelos professores da disciplina da FEA-USP inicia-se com o relato da experiência, possibilitando a construção de ponte entre a prática e a teoria e seguindo o preconizado por Kolb (1984) para a aquisição de um saber profissional. Vale destacar que, apesar de tais objetivos, o mestrado profissional confere o grau de mestre e por isso a importância de se resguardar os preceitos da metodologia científica, que proporcionará conhecimento também para que o futuro mestre possa atuar como docente e candidato a um futuro doutorado (BARROS, VALENTIM, MELO, 2005). 
Nos projetos analisados percebeu-se que esta categoria seguiu o resultado da categoria 'funil de pesquisa', dada a proximidade conceitual entre ambas, ou seja, a maioria dos alunos apresentou um relato da experiência vivenciada. Ao se colocar uma lente sobre os poucos trabalhos que assim não procederam, verifica-se que, provavelmente por falta de autorização da empresa para a realização da pesquisa, os alunos buscaram como saída a investigação de um setor e acabaram se perdendo na estruturação do capítulo introdutório, baseado na elaboração dos itens constituintes do funil de pesquisa (vide Figura 3).

\subsection{Reflexão sobre a experiência}

Nem todos os trabalhos se preocuparam com essa etapa do ciclo da pesquisa, fundamental na TAE. Para Kolb (1984), a experiência só produzirá conhecimento pela reflexão do que foi vivenciado, o que faz com que insira um sinal de alerta sobre tal questão. Mesmo assim, vários projetos consideraram esse aspecto, evidenciando o que tinham de experiência e o que de fato buscam resolver no mestrado profissional. Percebeu-se um pequeno acréscimo na turma $\mathrm{B}$, ingressante em 2015, possivelmente pela atenção que os docentes passaram a dar a essa categoria.

\subsection{Busca de embasamento teórico}

Etapa fundamental para a elaboração da etapa 4 do ciclo de pesquisa proposto, os alunos tiveram aula específica sobre como realizar a pesquisa bibliográfica, acessando as bases de dados disponíveis na universidade. Considera-se, portanto, que tiveram apoio necessário para a construção de uma base teórica preliminar que servisse de alicerce inicial para a elaboração de um pré-projeto.

Apesar desse cuidado, percebeu-se que este foi o ponto que os alunos demostraram maior resistência em sala de aula, a despeito do resultado positivo obtido com a análise do conteúdo dos projetos que constituíram o corpus da presente pesquisa.

Ressalta-se que quase todos os projetos - com exceção de um trabalho da turma $\mathrm{A}$ apresentaram o referencial teórico, porém foram considerados como ocorrência negativa nesta categoria também aqueles que não apresentaram um referencial suficiente para o embasamento preliminar da pesquisa e, consequentemente, não a estruturam de acordo com o funil teórico (vide Figura 4) proposto na diretriz do curso. 
Considera-se que a maioria dos alunos ainda necessitará aprimorar tal capítulo para a qualificação do projeto ou mesmo para a realização da pesquisa empírica, por isso foi tratado na disciplina como um levantamento preliminar.

\subsection{Relação teoria e prática}

Poucos foram os trabalhos que apresentaram, no encerramento da disciplina, a relação da teoria com a prática. Foi, então, sugerido aos alunos em sala de aula que elaborassem um quadro explicitando tal relação, de forma a facilitar o desenvolvimento de uma seção ou capítulo pertinente. Muitos alunos elaboraram esse quadro como atividade em sala de aula, porém não o incluíram no projeto entregue e nem avançaram, tampouco, com tal relação. Da mesma forma que a categoria 'reflexão sobre a experiência', percebeu-se um acréscimo na turma $\mathrm{B}$, talvez pelo maior estímulo fornecido em sala de aula.

Acredita-se que, pelo momento em que foi ofertada a disciplina, no início do curso, os alunos vão progredir nesse sentido, carecendo, porém, tal entusiasmo de verificação futura, quando da conclusão da dissertação.

\subsection{Adequação à área de concentração e à linha de pesquisa}

Todos os trabalhos foram considerados coerentes com a área de concentração de Empreendedorismo e às linhas de pesquisa: Inovação e Novos Negócios ou Empreendedorismo Interno.

Esse resultado não causa surpresa, pois todos os projetos analisados eram resultados dos anteprojetos de ingresso no mestrado profissional, e haviam sido analisados previamente pela banca de seleção. Portanto, a adequação à área e às linhas de pesquisa eram esperadas.

\section{CONSIDERAÇÕES FINAIS}

O foco deste estudo era analisar a estruturação do trabalho de conclusão de curso do mestrado profissional, a partir do caso da FEA-USP, especialmente no que tange a aplicações reais e práticas. A norma da CAPES já prevê essa distinção, no entanto, nota-se a difículdade de se produzir formatos distintos dos já consagrados mestrados acadêmicos.

Retomando ao questionamento apresentado na introdução da presente pesquisa tem-se que a diretriz proposta no mestrado profissional de empreendedorismo da FEA foi utilizada parcialmente pelos alunos ao elaborarem os projetos de pesquisa. Essa análise decorre do fato 
de que há pontos que precisam ser aprimorados, em especial a reflexão da experiência, etapa 2 do ciclo da pesquisa e a apresentação da relação da teoria com a prática, procedimento que faz parte da etapa 3 do ciclo de pesquisa.

As demais categorias específicas sobre a diretriz desenvolvida, se mostraram efetivas para a maioria dos projetos analisados, sendo que a estruturação dos capítulos introdutório e de referencial teórico com base no entendimento dos funis de pesquisa e teórico se fez presente na quase totalidade dos trabalhos de ambas as turmas analisadas.

Percebeu-se com a análise dos documentos que faziam parte do corpus da pesquisa que alguns pontos podem ser considerados vantajosos ao uso da diretriz para a estruturação do trabalho de conclusão desse mestrado profissional e outros precisam ser aprimorados. Como vantagens podem ser citados: (1) elaboração dos projetos em conformidade ao solicitado por todos os alunos investigados; (2) adequação à área de concentração e às linhas de pesquisa do mestrado profissional; (3) adequação tanto ao desenvolvimento de aspectos profissionais quanto ao método cientifico; (4) entendimento da necessidade de se realizar um recorte do que será investigado e da consequente questão de pesquisa; e (5) compreensão da necessidade de se estabelecer um referencial que fundamente teoricamente a pesquisa. Como pontos que podem ser aprimorados, destacam-se: (1) inserção da relação teoria e prática apresentada no funil de pesquisa, favorecendo o exercício; (2) desenvolvimento de projetos com estruturas mais criativas, considerando se tratar de mestrado profissional e não acadêmico; e, em menor grau, (3) maior reflexão dos alunos sobre a experiência vivenciada.

Dada a natureza exploratória do estudo, os resultados não são conclusivos e carecem de estudos futuros, como os relacionados à criatividade e a ausência da relação entre teoria e prática que não foram representativos nos projetos. Tal fato pode estar relacionado tanto com a diretriz, por propor uma estruturação já definida de projeto, quanto pelo momento em que se encontravam os alunos, ainda iniciando o curso.

Destaca-se, ainda, que as avaliações foram baseadas no referencial teórico dentre as categorias de análise estabelecidas previamente, e embora tenha resultado em avaliações díspares em alguns dos critérios, preferiu-se manter na íntegra os achados, porque as distinções foram pontuais e possivelmente só divergiram em termos subjetivos de análise, que são inerentes à atividade de pesquisa.

Estudos futuros podem ser sugeridos, como a avaliação das mesmas categorias analisadas na atual pesquisa na finalização do mestrado, ou seja, quando da defesa da 
dissertação; e a realização de estudo comparativo com alunos ingressantes nos próximos anos, de forma a avaliar a continuidade e implementação ou não das diretrizes propostas.

Ressaltam-se, ainda, as limitações deste estudo, tanto de cunho metodológico quanto prático. Trata-se de um trabalho exploratório e, por essa natureza, restrito ao contexto investigado, não possibilitando generalizações. Abre-se um parêntese para comentar que não é objetivo da pesquisa exploratória a generalização de dados e, portanto, o registro da limitação existente na própria natureza da pesquisa foi feito como alerta para futuros pesquisadores e leitores. Outras limitações práticas foram observadas: vieses podem ter sido causados pelo fato das análises serem decorrentes de pesquisadores envolvidos no desenvolvimento das diretrizes desse mestrado profissional e, portanto, conhecerem pessoalmente os problemas, desafios e limites, acentuando o anseio de que o seu uso seja adequado para alunos de mestrados profissionais.

\section{REFERÊNCIAS}

ALPERSTEDT, G. D. A.; BULGACOV, S.; PEREIRA, F. I.; VAllE, L. R. Mestrados profissionais em administração, contabilidade e turismo no Brasil e seu processo de avaliação. Revista Gestão Universitária na América Latina (GUAL), Florianópolis, v. 7, n. 1, jan. 2014, p.298-322.

ANTONELLO, C. S. Aprendizagem na ação revisitada e sua relação com a noção de competência. Comportamento Organizacional e Gestão, v. 12, n. 2, 2006, p.199-220.

BAKER, A. C.; JENSEN, P. J.; KOLB, D. A. Conversation as experiencial learning. Management Learning, v. 36 (4), 2005, p.411-427.

BARDIN, L. Análise de Conteúdo. Lisboa, Portugal: Edições 70, 1977; 2006.

BARROS, E. C. D.; VALENTIM, M. C.; MELO, M. A. A. O debate sobre o mestrado profissional na Capes: trajetória e definições. Revista Brasileira de Pós-Graduação (RBPG), v. 2, n. 4, jul. 2005, p.124-138.

CAPES - Fundação Coordenação de Aperfeiçoamento de Pessoal de Nível Superior. Portaria $\mathrm{n}^{\mathrm{o}} 80$, de 16 de dezembro de 1998. Dispõe sobre o reconhecimento dos mestrados profissionais e dá outras providências. Diário Oficial da República Federativa do Brasil, Brasília, DF, de 11 de janeiro de 1999, Seção I, p. 14. Disponível em: https://ebape.fgv.br/sites/ebape.fgv.br/files/portaria capes 080.pdf Acesso em: 29.10.2015.

CAPES - Fundação Coordenação de Aperfeiçoamento de Pessoal de Nível Superior. Portaria Normativa $\mathrm{n}^{\mathrm{o}} 17$, de 28 de dezembro de 2009. Dispõe sobre o mestrado profissional no âmbito da Fundação Coordenação de Aperfeiçoamento de Pessoal de Nível Superior CAPES. 
Diário Oficial da República Federativa do Brasil, Brasília, DF, de 29 de dezembro de 2009, Seção I, p. 20. Disponível em:

http://www.capes.gov.br/images/stories/download/legislacao/PortariaNormativa 17MP.pdf

Acesso em: 28.10.2015.

CAPES - Fundação Coordenação de Aperfeiçoamento de Pessoal de Nível Superior.

Documento de Área 2013: Área de Avaliação: Administração, Ciências Contábeis e Turismo. Brasília, DF, 2013. Disponível em:

http://www.capes.gov.br/component/content/article?id=4674:interdisciplinar

Acesso em: 29.10.2015.

CAPES - Fundação Coordenação de Aperfeiçoamento de Pessoal de Nível Superior. Mestrado Profissional: o que é? Brasília, DF, 2014. Atualizado em: 21 maio 2014. Disponível em: http://www.capes.gov.br/avaliacao/sobre-a-avaliacao/mestrado-profissional-oque-e

Acesso em: 02.04.2015.

CAPES - Fundação Coordenação de Aperfeiçoamento de Pessoal de Nível Superior. Relação de Cursos Recomendados e Reconhecidos. Grande área: Ciências Sociais Aplicadas. Área:

Administração. Brasília, DF, 2015. Disponível em:

$\mathrm{http}: / /$ conteudoweb.capes.gov.br/conteudoweb/?acao=pesquisarIes\&codigoArea $=60200006 \&$ descricaoArea $=\&$ descricaoAreaConhecimento=ADMINISTRA $\% 25 \mathrm{C} 7 \% 25 \mathrm{C} 3 \mathrm{O} \&$ descricao Ar eaAvaliacao=ADMINISTRA $\% 25 \mathrm{C} 7 \% 25 \mathrm{C} 3 \mathrm{O} \% 252 \mathrm{C}+\mathrm{CI} \% 25 \mathrm{CANCIAS}+\mathrm{CONT} \% 25 \mathrm{C} 1 \mathrm{BEIS}$ $+\mathrm{E}+\mathrm{TURISMO \#}$

Acesso em: 02.04.2015.

CNE - Conselho Nacional de Educação/ Câmara de Educação Superior. Resolução CNE/CES n. 1: Estabelece normas para o funcionamento de cursos de pós-graduação, Brasília, DF, 3 abr. 2001.

CNE - Conselho Nacional de Educação/ Câmara de Educação Superior. Resolução CNE/CES n. 24: Altera a redação do parágrafo $4^{\circ}$ do artigo $1^{\circ}$ e o artigo $2^{\circ}$, da Resolução $\mathrm{CNE} / \mathrm{CES}$ $1 / 2001$, que estabelece normas para o funcionamento de cursos de pós-graduação, Brasília, DF, 18 dez. 2002.

FESTINALLI, R. C. A formação de mestres em administração: por onde caminhamos? Organização \& Sociedade, v.12, n.35, Outubro/Dezembro - 2005.

FISCHER, T. Seduções e riscos: a experiência do mestrado profissional. Revista de Administração de Empresas (RAE), v. 43, n. 2, abr.-jun. 2003, p.119-123.

FLICK, U. Introdução à Pesquisa Qualitativa. 3. ed. Porto Alegre: Artmed, 2009.

GIL, A. C. Como Elaborar Projetos de Pesquisa. 5. ed. São Paulo: Atlas, 2010.

GIL, A. C. Métodos e Técnicas de Pesquisa Social. 6. ed. São Paulo: Atlas, 2012. 
HAIR JR., J. F.; BARRY, B.; MONEY, A. H.; SAMOUEL, P. Fundamentos de Métodos de Pesquisa em Administração. Porto Alegre: Bookman, 2005.

KOLB, D. A. Experiential Learning: experience as the source of learning and development. New Jersey: Prentice Hall, 1984.

KOLB, A. Y.; KOLB, D. A. Learning styles and learning spaces: Enhancing experiential learning in higher education. Academy of Management Learning and Education, v. 4, 2005, p. 193-212.

MARIOTTO, F. L.; ZANNI, P. P.; MORAES, G. H. S. M. What is the use of a single-case study in management research? Revista Administração de Empresas (RAE), v. 54, n.4, Julho/Agosto 2014.

OSGOOD, C. E. The representational model and relevant research methods. In: POOL, I. de S. Trends in Content Analysis. Urbana, IL: University of Illinois Press, 1959, p.33-88.

PIMENTEL, A. A teoria da aprendizagem experiencial como alicerce de estudos sobre desenvolvimento profissional. Estudos de Psicologia, v. 12, n. 2, p.159-168, 2007. Disponível em: http://www.scielo.br/scielo.php?pid=S1413294X2007000200008\&script $=$ sci arttext

Acesso em: 29.10.2015.

RIBEIRO, R. J. O mestrado profissional na política atual da Capes. Revista Brasileira de Pós-Graduação (RBPG), Brasília, v. 2, n. 4, jul. 2005, p.8-15.

RIBEIRO, R. J. Ainda sobre o mestrado profisssional. Revista Brasileira de Pós-Graduação (RBPG), Brasília, v. 3, n. 6, dez. 2006, p.313-315.

RUAS, R. Mestrado modalidade profissional: em busca da identidade. Revista de Administração de Empresas (RAE), v. 43, n. 2, abr.-jun. 2003, p.55-63.

SELLTIZ, C.; WRIGHTSMAN, L.; COOK, S. Métodos de pesquisa nas relações sociais. $4^{a}$. ed. São Paulo: E.P.U., 1987.

SHARLANOVA, V. Experiential learning. Trakia Journal of Sciences, v. 2, n. 4, 2004, p.36-39.

VASCONCELOS, F. C. D.; VASCONCELOS, I. F. G. D. Réplica 1 - As dimensões e desafios do mestrado profissional. Revista de Administração Contemporânea (RAC), v. 14, n. 2, mar.-abr. 2010, p.360-366. 